\title{
Article \\ Wind farm noise management based on determinants of annoyance
}

\author{
Frits van den Berg
}

Mundonovo sound research, Baflo, the Netherlands, email: fvdberg@mundonovo.nl

\begin{abstract}
Wind energy in Europe is aimed to grow at a steady, high pace. Wind turbine noise is an important issue for residents. Environmental noise management aims to reduce the exposure of the population, usually based on acoustics and restricted to a limited number of sources (such as transportation or industry) and sound descriptors (such as $\mathrm{L}_{\mathrm{den}}$ ). Individual perceptions are taken into account only at an aggregate, statistical level (such as percentage of exposed, annoyed or sleep-disturbed persons in the population).

Individual perceptions and reactions to sound vary in intensity and over different dimensions (such as pleasure/fear or distraction). Sound level is in fact a weak predictor of the perceived health effects of sound. The positive or negative perception of the sound (source) is a better predictor of its effects.

This article aims to show how the two perspectives (based on acoustics and on perception) can lead to a combined approach in the management of environmental sound. In this approach the reduction of annoyance, not primarily of level, is the main aim. An important aspect in this approach is what a sound means to people: does it lead to anxiety or worry, is it appropriate? The available knowledge will be applied to wind farm management: planning as well as operation.
\end{abstract}

Keywords: wind turbine, noise annoyance, fear, worry, noise sensitivity, noise management

\section{Introduction}

In 2020 wind energy installations in Europe had a total capacity of $220 \mathrm{GW}$ [1]. This corresponded to $16 \%$ of the electricity consumed in 2020 in the EU+UK, where electricity consumption is about $22 \%$ of total energy consumption in Europe [2]. This was expected to grow in the next few years with 15 to $20 \mathrm{GW}$ per year [1], but recently the EU set a new target of $30 \mathrm{GW}$ per year to arrive at a total of $451 \mathrm{GW}$ in 2030 [3]. However, this will depend on how national and local authorities in Europe (and elsewhere) are able to balance the need for renewable (wind) energy with the growing opposition to wind farms (e.g. see $\left.{ }^{4}\right]$ ). Opposition from residents is mainly based on worries about the impact on health. It has been shown that health effects on residents near wind farms are related to exposure to and annoyance from the wind turbines, but also to other factors such as participation in the planning process, procedural justice, feelings of fairness and balance of costs and benefits from wind turbines [5]. Simos et al concluded from their review that when wind turbines are erected, persons in their neighbourhood may experience anxiety and distress, though annoyance is the only symptom backed up by solid scientific evidence [ $\left.{ }^{6}\right]$.

In this paper we consider factors that have an influence on the perception of annoyance or negative feelings and associations from a noise source in general and a wind farm in particular. This will be based on general knowledge of (psycho)acoustics and health effects from noise (including annoyance), and supported by the more limited knowledge from wind turbines noise effects. As a consequence we conclude that environmental management of a wind farm based on noise exposure can be improved by focusing on annoyance reduction.

\section{Meanings of sounds ${ }^{1}$}

Noise is unwanted sound whereas 'sound' lacks the explicit negative notion of noise. In psychological terms sound can have different affective (i.e. related to emotion) dimensions: arousing, exciting, pleasant, relaxing, sleepy, gloomy, unpleasant, distressing [7]. Annoying, the only affective aspect used in

\footnotetext{
1 The text in 2. and 3.1 summarizes part of a text in Dutch: F. van den Berg, Positieve effecten in book "Geluid en Gezondheid" ("Positive effects" in "Sound and health"), Sdu Uitgevers, Den Haag (Netherlands), 2013

1 of 8
} 
environmental assessments, is in between exciting and distressing and the opposite of relaxing rather than pleasant [ $\left.{ }^{8}\right]$.

Environmental sound usually refers to sound from transport sources and business activities, but can extend to all sounds in the (home) environment. In practice environmental sound levels extend from about $20 \mathrm{~dB}(\mathrm{~A})$ to less than $80 \mathrm{~dB}(\mathrm{~A})$. At both ends of this range there is generally agreement about the perceived quality: very quiet and very noisy, respectively. But in between there is a broad range where some find the situation noisy and others do not. This is illustrated in Fig. 1 where respondents near Dutch wind farms at any specific sound level in the range 30 to $>45 \mathrm{~dB} \mathrm{~L}_{\text {den }}$ gave qualifications ranging from 'don't hear' to 'very annoying' [ $\left.{ }^{9}\right]$. The acoustic quality of the sound and a host of other 'non-acoustic' factors are at the base of these

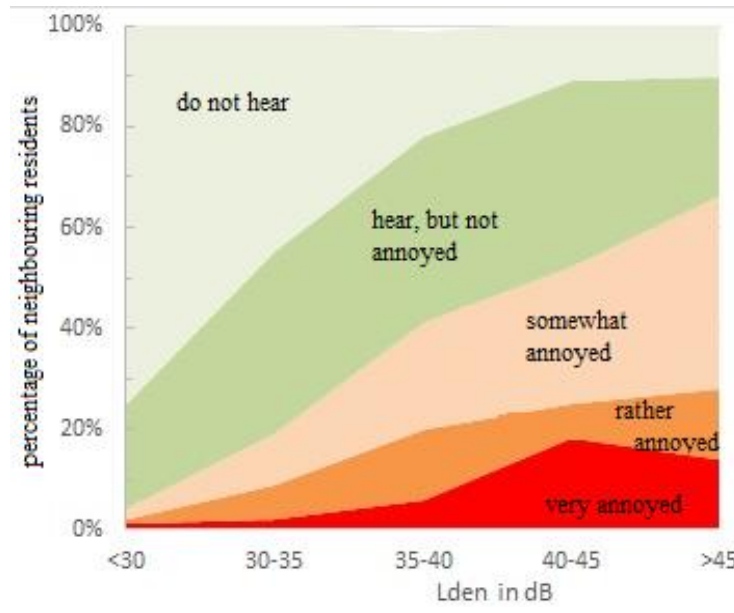

Fig. 1. Reactions to wind turbine noise differences.

In analogy with the visual qualities of a landscape, the aural qualities of a soundscape have been described by Schafer [10]. With sound we communicate with the soundscape, our audible environment. The environment constantly lets us know what's going on: whether something requires attention or everything is as expected. In reverse we communicate with the environment: others hear us coming, we talk, call, greet, sing or are quiet. In this context, noise can be defined as sound that restrains our ability to communicate with the physical, natural and social environment [11]. Despite our visually oriented image culture, sound remains important. Indeed, we cannot 'look away' from sounds, we cannot but hear every audible sound. This need not lead to a conscious perception: when unconscious processing in the brain recognizes the sound as 'safe' and 'appropriate' it may remain unconscious. If we want to shut out noise (e.g. with ear phones or ear plugs), we also shut out other sounds and lose contact with the environment.

Sound is evaluated at several levels: as an immediate, unconsciously processed impression; its information content; its relation to the context present; its loudness [12]. Playing children 'belong' in many home environments, but not at night or in an industrial environment. Also, the sound of playing children has an influence on road traffic sound: the total sound is experienced as "better" and "more natural", but not "more calm" than the road traffic itself $\left.{ }^{13}\right]$. At the same physical sound levels pleasant sounds are experienced as less loud than unpleasant sounds [14].

\section{Perception and annoyance}

\subsection{Perception}

People are very different from sound meters: we do not hear sound as an acoustic presence, but as a representation of a source. When we hear a sound, we cannot but associate it with a source. There is no 'acoustic' impression or observation, but a voice that speaks or a dog that barks, a car or a bicycle bell: we hear what causes the sound [15]. If consciously heard, this leads to associations: the pleasure of a familiar voice, the fear of damage from a billowing storm, the expected sleep disturbance from the nearby wind farm. The sound as such is not the cause of stress or fear, but the awareness of the source of sound is. Thus, a wind turbine is not perceived as a neutral object, a vertical bar with three 'spokes' on top, but as a human-built machine that may summon positive or negative associations.

People see, hear, feel, smell -in short: experience- all aspects of an environment at the same time with each person's personal associations. Coherence between different aspects of perceptions is important for the total sensation. For example: a visually highly regarded natural environment is less appreciated when unnatural, mechanical sounds are heard [12]. In a nationwide survey Van Rompaey et al. [16] used pictures of various landscapes with or without wind turbines. A visual quality index was based on the percentage of forest, built up area, hilliness/flatness, and absence/presence of human elements. The survey results 
showed that wind turbines affected the visual quality: low quality landscapes were perceived as improved, high quality landscapes as degraded. According to Frantal et al. [17] the influence of wind turbines on visual aspects of the landscape is highly dependent on the local environmental and socioeconomic context. Also, annoyance from the visual presence of wind turbines may add to and even reinforce the noise-related annoyance (and vice versa).

\subsection{Annoyance and other health effects}

It is generally assumed there is a monotonous increase of the percentage of annoyed persons when the noise level increases. But level explains only part of individual annoyance. In a large number of studies Job [18] found relations between sound level and individual annoyance with correlation coefficients (c.c.) varying from 0.22 to 0.61 with a mean value of 0.42 . This means that the variance (square of c.c.) was 0.04 to 0.37 , with an average of 0.17 or $17 \%$. This $17 \%$ is the degree in which the noise annoyance is explained by noise level. Almost 30 years later Brink [19] reported similar values, generally variances were from 0.1 to 0.2 . The annoyance at group level (groups with each many individuals) was better correlated to noise level with a variance of 0.31 to 0.98 and an average of 0.67 .

For wind turbine sound, correlation coefficients were found in the same range. In a Dutch survey Pedersen et al. $\left[{ }^{20}\right]$ found a c.c. between wind turbine sound level and annoyance of 0.51. In an earlier Swedish study [21] the c.c. was 0.42 .

In the context of the WHO noise guidelines Basner and McGuire [22] concluded that transportation (air, road, rail traffic) noise has a direct effect on sleep as it influenced objectively measured physiological measures of sleep. But they also concluded that sound level may not directly influence self-reported sleep disturbance, but indirectly through individual factors: "This suggests that for self-reported measures it is annoyance or attitude to the night-time noise that may be driving the increase of reported sleep disturbance outcomes with $L_{\text {night }}$ level" [22]. Van den Berg et al. [23] found similar results from a survey that investigated noise annoyance and self-reported sleep disturbance from various noise sources (transportation, neighbours, industry): correlation coefficients between both effects varied from 0.75 to 0.84 and the annoyance thus explained $56-70 \%$ of the variation in sleep disturbance. This is high in comparison to noise level which explains on average only $10 \%$ of self-reported sleep disturbance [24]. Meaningful noise may disturb sleep more than meaningless or neutral noise [23, 25]. For example: 'meaning' could be a perception of inconsiderateness or even malignancy and thus may be related to the attitude towards the source. It has been shown for wind turbines and church bells that attitude can influence the effect of noise [20, 26]. Michaud et al. found that self-reported sleep disturbance was not related to WT sound level, but closing the window because of sleep disturbance had a strong association with annoyance [27].

Cardiovascular health effects such as ischaemic heart disease and hypertension have also been found to correlate with (high) sound levels [ ${ }^{28}$. Although a direct effect of sound cannot be ruled out, it is plausible that cardiovascular effects are the result of noise-induced stress [29].

Chronic annoyance can lead to stress and this is probably the most important route leading to further health consequences [30]. For wind turbines there is no clear evidence that the sound level is related to sleep disturbance, stress or other health effects, but there is a correlation between such effects and annoyance [5, 31]. Michaud et al. [32] have shown that the sum of annoyances from noise, blinking lights, flicker shadow, visual impact and (to a lesser extent) vibrations are correlated to perceived health symptoms.

\subsection{Factors influencing noise annoyance}

Miedema et al. [33] collected survey responses from about 64,000 respondents to determine the relation between sound level and annoyance with respect to transportation sound. They also investigated factors that could influence this relation [34], using data from almost 43,000 respondents in 34 studies. Eight of these factors were demographic (gender, age, level of education, occupation, household size, homeownership, dependency on and use of noise source), two were 'attitudinal variables' related to personal traits (fear of noise source and noise sensitivity). The response for each variable was assigned to a number of categories, e.g. four categories of education level ( $1^{\text {st }}$ level to university level) or three categories of noise sensitivity (tertiles of 0-100 scale). The results showed that noise annoyance was not related to gender, but significantly related to the other demographic factors, albeit to a low or very low degree. In nearly all cases the extra noise annoyance related to each factor was equivalent to a change in Day-Night-Level DNL $\left(=\mathrm{L}_{\mathrm{dn}} \approx \mathrm{L}_{\mathrm{den}}\right)$ of -2 to $+2 \mathrm{~dB}$. Larger effects were found for young (10-20 years) and 
old persons $(70+)$ and those economically dependent on the noise source in question: they were relatively less annoyed (equivalent to 4,3 and $2.6 \mathrm{~dB}$, respectively). In contrast, the personal factors noise sensitivity and fear had a far bigger influence on noise annoyance. Noise sensitivity was assessed with a single question ('Are you sensitive to noise?"); the extra annoyance for those high sensitive (upper tertile) was equivalent to $11.2 \mathrm{~dB} \mathrm{~L}_{\mathrm{dn}}$ when compared to the low sensitive persons (lower tertile). In the reviewed studies fear was assessed with different questions, but all were related to aircraft/road/rail accidents. Fear had an even stronger effect: the extra annoyance in the highest tertile was equivalent to $19.5 \mathrm{~dB} \mathrm{~L}_{\mathrm{dn}}$ when compared to the lowest tertile. Miedema et al. [34] suggested that this effect could be because of a (personal) disposition towards fear or an actual experience of fear.

The relation between annoyance and worry -one of the expressions of fear- has been investigated by Van den Berg et al. [35] who used results from an environmental health survey in the Amsterdam area. Respondents were asked if they were annoyed by a number of noise and odour sources and if they were worried about it possible hazards. Answers to these questions were given on an 11-point scale, ranging from 0 (not annoyed/worried at all) to 10 (extremely annoyed/worried). The list of nine noise sources as well as the list of five odour sources included road traffic and aircraft. The list of thirteen possible hazards included situations related to road traffic and aircraft: living in a busy street, living close to an airport and living under the air route of a main airport. The coefficient for the correlation between annoyance scores from road traffic and worry scores of those living near a busy road was 0.49 and for odour annoyance and living near a busy road was 0.46 . For aircraft noise annoyance and living near an airport or near an air route, the correlation coefficient was higher: 0.63 and 0.59 , respectively. Associations between aircraft odour annoyance and living near an airport or near an air route had correlation coefficients of $0.57 / 0.56$. On average the annoyance score increased with two units for every unit increase in worry score; this applied to noise as well as odour annoyance. Further results suggested that being worried seemed to be related to a disposition as worry scores for very different situations were also significantly correlated. For the 78 possible pairs of worry scores each correlation coefficient was $\geq 0.45$ and in half of the cases even $\geq$ 0.60. This may be obvious for related situations (e.g. living near an airport and living near an air route), but less so for unrelated situations (e.g. living near an airport and living below sea level). However, results showed that correlation coefficients for unrelated pairs were not clearly lower than for related pairs.

The large contribution of worry to annoyance from wind turbine noise has been confirmed in the Canadian Noise and Health Study [27] where the contribution of all personal and situational variables included in the survey to noise annoyance was studied. Eleven variables explained most of the noise annoyance. Of these, six variables concerned a response to wind turbines (closing bedroom window due to wind turbines, annoyance from blinking lights/vibration/sight, self-reported sleep disturbance, complaints about wind turbines), together leading to a variance of 0.46 . This means that all these reactions to the wind farm operation explained $46 \%$ of the annoyance from noise. The others factors, including sound level, explained a further $14 \%$. When the variables were restricted to those that were expected not to be a direct response to wind farm operations, the resulting eight variables explained $40 \%$ of the noise reaction. Here the single most important factor was concern about physical safety (explaining $17 \%)$, followed by wind turbine sound level (11\%) and noise sensitivity (7\%).

Fear is an important driver of animal and human behaviour. According to Wikipedia "fear is an emotion induced by perceived danger or threat, which causes physiological changes and ultimately behavioural changes, such as mounting an aggressive response or fleeing the threat. Fear in human beings may occur in response to a certain stimulus occurring in the present, or in anticipation or expectation of a future threat perceived as a risk to oneself (....). In humans and other animals, fear is modulated by the process of cognition and learning. Thus, fear is judged as rational or appropriate and irrational or inappropriate." [36] Thus, feelings of fear or worry (which is an anticipation of fear) are not necessarily based on actual or 'objective' danger such as acknowledged by institutions or authorities, but can be based on individual perceptions, beliefs and/or cognitive or attitudinal dispositions. These individual positions may be influenced by the community: "individuals' fears (....) are also shaped by their social relations and culture, which guide their understanding of when and how much fear to feel." [36]

\section{Application to noise management}

\subsection{General considerations}

From the previous sections it can be concluded that: 
- noise annoyance is the primary reaction to noise (i.e. sound that disturbs).

- further health effects are likely to result from chronic noise annoyance, although a direct physiological effect of sound is not excluded.

- annoyance from a noise source is related to the sound level from that source, but only to a modest degree; other factors contribute substantially to noise annoyance.

- of these other factors fear or worry in relation to the noise source and noise sensitivity appear to be the most important factors. Because of beliefs, associations and experiences with the sound source and possibly of characteristics of the sound it may carry a meaning that the presence of the sound source is 'unsafe'.

From this we can infer that reduction of the impact of environmental sound can be reached in different ways. One way is to reduce the impact of sound as such, either by reducing sound level or by reducing annoying characteristics of the sound (such as tonal content) or other exposures from the same source. A second way is to reduce negative perceptions of and/or associations with the noise source. This of course is neither simple nor straightforward as the perceptions and associations may, at least in part, be realistic and reasonable. But they can also have another cause: amongst others, earlier experiences or 'fear of the unknown' or a lack of control can play a role. Several questionnaires have been developed to assess worry in general $\left.{ }^{37}\right]$ or worry related to environmental sources [ $\left.{ }^{38}\right]$. A single question is also used, such as 'When you see or hear ....., how often do you feel there is some danger that ....?' [29] or "Which of the following situations applies to you? Please tick these and then indicate whether you are worried about your safety/health in this situation" [30]. To explore this way of reducing annoyance it is also necessary to consult members of the exposed population as any mitigation measures should diminish worry in that population. The third important factor, noise sensitivity, cannot be reduced by itself as it is a stable, individual characteristic. But a reduction in sound level and noticeable characteristics will help. Apart from that, awareness of noise sensitivity may be of use in noisy areas: if the sound level cannot be reduced, it may help to warn people who consider moving there when they think of themselves as being noise sensitive. Noise sensitivity can be assessed with a number of scales or (less accurately) with a single question [39].

\subsection{Wind farm annoyance}

The general conclusions in the previous section also apply to the case of wind farms. In a recent review of the residential effects of wind turbine noise Van Kamp and Van den Berg [25] conclude that health complaints (other than annoyance) related to wind farms are primarily related to annoyance which again depends on a range of non-acoustic factors and the actual exposure. Such factors include "noise sensitivity, attitudes towards wind turbines, health concerns, visual aspects and aspects related to the procedure preceding the building of a wind park. The role of factors such as participation in the planning process, procedural justice, feelings of fairness and balance of costs and benefits from wind turbines are even more strongly supported by current evidence" [25]. It is not just the sound from a wind farm, but also visual effects and perhaps vibrations that can lead to annoyance.

Citizens confronted with wind farm plans in their area worry about the consequences for their health and other environmental effects (such as animal mortality). Not taking these worries seriously is likely to fuel more opposition. At least part of the worry is not unreasonable as many national limits for noise and shadow flicker do not exclude the occurrence of (severe) annoyance and possible further health consequences. Thus, some residents will be affected if the wind farm is built and operational, and worrying about this in the planning phase may lay the roots for annoyance in the operational phase. On the other hand, at least a measure of severe annoyance (and possible further health consequences) is generally considered acceptable when it concerns transport noise. Also, if society does not embrace renewable energy in the short term, there will be serious other public health consequences related to climate change.

The present approach to environmental effects is based on 'objective' quantities: sound level, shadow flicker time and safety risks. Usually these are calculated and it may be impractical or even impossible to measure these quantities locally. However, most residents do not care that much about objective limits: they do not want to be affected by the presence of the wind farm, especially not when the pros and cons are out of balance. In the recent international Wind Turbine Noise Conference 2021 this was explored in two sessions concerning 'being good neighbours' in relation to wind farms. Employees of a wind farm operator told that they want to reduce annoyance from the wind farm as much as practical and residents near a wind farm said they would welcome efforts of their neighbouring wind farm operator to reduce the impact on residents. However, these intentions yet had to be implemented. This sounds familiar when 
consulting the scientific literature about social resistance to wind farm plans: "There is increasing evidence that annoyance is lower when people can participate in the siting process. Worries of residents should be addressed in an early stage, by involving them in the process of planning and decision making" [25]. Simos et al. state that "The empowerment of affected populations is a central tenet of health promotion. Its efficacy and usefulness have been demonstrated in many settings across the world. Empowerment also tends to increase the acceptability of projects" [d].

\subsection{Proposed approach: reduction of annoyance from wind farms}

The preceding information suggests that a noise management approach based on reducing annoyance as much as possible seems to be promising. It is also a way to express good neighbourliness which should be pursued in order to achieve sustainable energy goals. Of course, it may not eliminate annoyance entirely as it seems unlikely to find solutions for every individual neighbouring resident. This approach is in fact an application of the ALARA principle (As Low As Reasonably Achievable), where 'reasonable' is an optimal balance between the cost of mitigation and the reduced exposure of the target group. EAN, the European ALARA Network strives to apply this principle "for the management of occupational and public exposures and patients in all exposure situations" $\left[{ }^{40}\right]$, though as yet it has not been applied to wind energy. General measures would apply to the population near the wind farm and can be based on what we know about residential effects of wind farms. An individual perspective may help to understand residential reactions, certainly with respect to persons who are affected more than average because of their situation or their condition.

Noise annoyance management can be based on measures in the planning phase and in the operational phase. This is part of a process that acknowledges the importance of other factors such as mentioned above (participation in planning process, procedural justice, feelings of fairness, balance of costs and benefits, other exposures).

Planning phase:

- It is important to respect residents' worries in relation to the planned wind farm and to address these in an early stage.

- Minimize impact: no (or as little as possible) flicker shadow; wind turbines with below-average sound production; no permanently blinking aircraft warning lights; consideration of visual impact.

- Perhaps other measures can be discussed, such as synchronization of the wind turbines' rotation or possibilities to reduce the rhythmic sound character (amplitude modulation).

- For the most impacted and/or vulnerable residents individual mitigation measures are possible, such as planting trees, moving the bedroom to the quiet side, adding insulation, etc.

- In the planning phase it is important to install trust that mitigation measures in the operational phase, where necessary, will be implemented and which financial and technical means are available to do this.

Operational phase:

- As amplitude modulation (AM) of wind turbine sound is an important characteristic and in annoyance equivalent to an increase of sound level of 3 to $5 \mathrm{~dB}$ or more, reduction of this can have a significant effect. Only one case study has been reported that concerned AM mitigation [ $\left.{ }^{41}\right]$.

- Residents can be consulted about the actual impact of the wind farm, and especially about situations where the annoyance is above average. Consultation is possible with representatives from the community (sounding board group), periodic meetings and/or more permanent communication means (website, app, complaint desk).

- It is reasonable that a wind farm operator sets funds aside to implement mitigation measures.

Simos et al. [d] mention some practical issues and give recommendations for mitigation measures that partly overlap the recommendations above.

\section{Conclusion}

The opposition of residents and other groups in society to wind energy plans is likely to slow down the transition to sustainable energy. To be able to achieve the goals the European Union set for 2030 it will help to understand worries of residents near projected wind farms and act to reduce these worries. 
Funding: this research received no external funding.

Conflicts of interest: The author declares no conflict of interest.

\section{References}

1 Wind Europe. Wind energy in Europe - 2020 Statistics and the outlook for 2021-2025. Report Wind Europe, 2021

2 Eurostat. Statistics explained- Energy statistics - an overview. (https://ec.europa.eu/eurostat/statisticsexplained/index.php?title=Energy_statistics_-_an_overview\#Final_energy_consumption, consulted 29-12-2021)

3 Wind Europe. The EU Commission wants $30 \mathrm{GW}$ a year of new wind up to 2030. (https://windeurope.org/newsroom/press-releases/its-official-the-eu-commission-wants-30-gw-of-new-winda-year-up-to-2030/, consulted 29-12-2021)

4 J. Shankleman, L. Paulsson. As windpower grows in Europe, so does resistance from locals. . Bloomberg Business, 19-6-2020 (www.bloomberg.com/news/articles/2020-06-19/wind-power-and-turbines-are-facing-pushbackfrom-europe-s-locals, consulted 30-6-2021)

5 I. van Kamp, F. van den Berg. Health effects related to wind turbine sound: an update. J. Environ. Res. Public Health 18, 2021

6 J. Simos, N. Cantoreggi, D. Christie, J. Forbat. Wind turbines and health: a review with suggested recommendations. Environ Risque Sante 18:1-11. 2019

7 J. Russell, G. Pratt. A description of the affective quality attributed to environments. Journal of Personality and Social Psychology, 38(2):311-322, 1980

8 K. Craik. Environmental perception and environmental annoyance: issues of measurement and interpretation. Proc. proceedings Intern Symp Environmental Annoyance, Woudschoten, the Netherlands, 1987

9 Data from Project WINDFARMperception. F. van den Berg, E. Pedersen, J. Bouma, R. Bakker. Visual and acoustic impact of wind turbine farms on residents. Final report UMCG/University of Groningen, 2008

10 R. Murray Schafer. The soundscape: Our sonic environment and the tuning of the world. Destiny Books, Rochester Vt (USA), 1977

11 K. Altena. Noise annoyance and loss of value. Proc. Intern. Symp. Environmental Annoyance, Woudschoten, 1986

12 J. Carles, I. Barrio, J. de Lucio. Sound influence on landscape values. Landscape and Urban Planning 43:191-200, 1999

13 K. Kawai, T. Yano. A study on the effects of individual sounds on the psychological evaluations of combined environmental sounds. Proc. Internoise98, Christchurch, 1998

14 S. Namba, S. Kuwano. Psychological study on Leq as a measure of loudness of various kinds of noise. J. Acoust. Soc. Japan (E) 5 (3):135-148, 1984

15 C. Fowler. Auditory perception is not special: We see the world, we feel the world, we hear the world. J. Acoust. Soc. Am. 89(6):2910-2915, 1991

16 A. Van Rompaey, V. Vanderheyden, S. Schmitz, Modelling the impact of wind turbines on the visual attractivity of landscapes at a regional scale. Proc. European Wind Energy Conference, Brussels, 2008

17 B. Frantál, D. Van Der Horst, J. Kunc,M. Jaňurová. Landscape disruption or just a lack of economic benefits? Exploring factors behind the negative perceptions of wind turbines. Journal of Landscape Ecology, 15(2):139-47, 2017

18 R. Job. Community response to noise: A review of factors influencing the relationship between noise exposure and reaction. J. Acoust. Soc. Am. 83(3):991, 1988

19 M. Brink. A review of explained variance in exposure-annoyance relationships in noise annoyance surveys. Intern Congress Noise as a Public Health Problem (ICBEN), Nara, 2014

20 E. Pedersen, F. van den Berg, R. Bakker, J. Bouma. Response to noise from modern wind farms in The Netherlands. J. Acoust. Soc. Am. 126(2):634-643, 2009

21 E. Pedersen, K. Persson Waye. Perception and annoyance due to wind turbine noise-a dose-response relationship. J. Acoust. Soc. Am. 116 (6):3460-3470, 2004

22 M. Basner, S. McGuire. WHO environmental noise guidelines for the European region: A systematic review on environmental noise and effects on sleep. Intern. J. Environmental Research and Public Health 15(3), 2018

23 F. van den Berg, C. Verhagen, D. Uitenbroek. The relation between scores on noise annoyance and noise disturbed sleep in a public health survey. Int. J. Environ. Res. Public Health 2014, 11(2):2314-2327

24 H. Miedema, H. Vos. Associations between self-reported sleep disturbance and environmental noise based on reanalyses of pooled data from 24 studies. Behav. Sleep Med. 5:1-20, 2007

25 S. Kuwano, T. Mizunami, S. Namba, M. Morinaga. The effect of different kinds of noise on Quality of sleep under the controlled conditions. J. Sound Vib. 250: 83-90, 2002

26 M. Brink, S. Omlin, C. Müller, R. Pieren R, M. Basner. An event-related analysis of awakening reactions due to nocturnal church bell noise. Science of the Total Environment 409, 2011

27 D. Michaud, S. Keith, K. Feder, S. Voicescu, et al.. Personal and situational variables associated with wind turbine noise annoyance. J. Acoust. Soc. Am. 139(3), 2016 
28 E. Van Kempen, M. Casas, G. Pershagen, M. Foraster. WHO environmental noise guidelines for the European region: a systematic review on environmental noise and cardiovascular and metabolic effects: a summary. International journal of environmental research and public health, 15(2):379, 2018

29 H. Ising W. Babisch B. Kruppa. Noise-induced endocrine effects and cardiovascular risk. Noise Health 1:37-48, 1999

30 C. Clark, S. Stansfeld. The Effect of Transportation Noise on Health and Cognitive Development:A Review of Recent Evidence. Intern J Comparative Psychology, 20 (2), 2007

31 WHO, Environmental Noise Guidelines for the European Region (2018) WHO, Bonn

32 D. Michaud, L. Marro, J. McNamee. The association between self-reported and objective measures of health and aggregate annoyance scores toward wind turbine installations. Canadian journal of public health 109(2): 252260,2018

33 H. Miedema, Henk Vos. Exposure-response relationships for transportation noise. J. Acoust. Soc. Am. 104(6), 1998

34 H. Miedema, Henk Vos. Demographic and attitudinal factors that modify annoyance from transportation noise. J. Acoust. Soc. Am. 105 (6), 1999

35 F. van den Berg, C. Verhagen, D. Uitenbroek. The Relation between Self-Reported Worry and Annoyance from Air and Road Traffic. Int. J. Environ. Res. Public Health 12(1), 2015

36 Wikipedia, lemma "Fear"( https://en.wikipedia.org/wiki/Fear), consulted 29-6-2021

37 G. Davey. A comparison of three worry questionnaires. Behaviour Research and Therapy, 31(1), 1993

38 S. Cruz, B Manata. Measurement of Environmental Concern: A Review and Analysis. Frontiers in Psychology 11, 2020

39 K. Zimmer, W. Ellermeier. Psychometric properties of four measures of noise sensitivity: A comparison. Journal of Environmental Psychology, 19(3), 1999

40 EAN. Statuts du Reseau ALARA Europeen: But et composition de l'association (in French). Retrieved from https://www.eu-alara.net/index.php/presentation.html, 4-1-2022

41 M. Cand, A. Bullmore. Measurements demonstrating mitigation of far-field AM from wind turbines. Intern. Meeting Wind Turbine Noise, Glasgow, 2015 